\title{
The incidence and risk factors of hypocalcaemia after thyroid surgery
}

\author{
Aws B. Abed* \\ FICS \\ Mohannad K. Al Bermani* FICS \\ Waleed A. Salman* $\quad$ FICS
}

\section{Abstract:}

Background: Hypocalcaemia is a well-recognized complication of thyroid surgery. It is most often transient event that occurs after extensive thyroid resection that may require calcium and/or vitamin D supplements to alleviate or prevent the symptoms.

Fac Med Baghdad 2018; Vol.60, No.1 Received: Jan, 2017 Accepted: Mar., 2018
Objective: of this study is to determine the incidence of hypocalcaemia after thyroid surgery and find out the risk factors involved regarding the patient age, gender, and muscular built, clinical diagnosis, extent of surgery, ligation of the inferior thyroid artery, pathology report and the experience of the surgeon.

Patients and methods: This prospective study was carried out on 100 patients who underwent thyroid surgery for various thyroid diseases at the surgical department of Baghdad teaching hospital in the period between November 2009 to November 2013.Serial serum calcium measurements were recorded as well as details of the operation, patient age and gender, ligation of the inferior thyroid artery or not, pathological report and experience of the operator. Hypocalcaemia was considered transient if it was resolved within 6 months and permanent if it persisted after 6 months and the patient was maintained on supplementation therapy of calcium and vitamin D.

Results: We found that the incidence of post-thyroidectomy hypocalcaemia was $30 \%$ and in the majority of the cases $(24 \%)$ was transient, while it was permanent in only (6\%) of cases and had occurred mainly after total thyroidectomy and in cases with ligation of the inferior thyroid artery.

Conclusions: We concluded that post thyroidectomy hypocalcaemia is a relatively common complication, but it is transient in the majority of the patients. Its incidence is related to the extent of the surgery and can be reduced by the use of the correct surgical procedures.

Key words: hypocalcaemia, post thyroidectomy, total thyroidectomy, subtotal thyroidectomy.

\section{Introduction:}

Postoperative hypocalcaemia is one of the complications of thyroidectomy; its incidence is more common after total thyroidectomy than after other more conservative thyroidectomies. (1) It usually manifests itself in the first 24 hours post operatively or within the 2 - 3 days after operation, however, very rarely the onset is delayed 2-3 weeks. (1) Most patients it is transient that resolves spontaneously and only few patients develop permanent hypocalcemia $(.2,3)$ In $80 \%$ of cases it resolves in about 12 months. 4 The risk of this complication depends on the extent of surgery, the nature of the underlying disease and the experience of the operating surgeon. Furthermore, specific surgical problems are encountered in cases of recurrent thyroid disease, large goiter, anatomical variations, retrosternal or even mediastinal location and damage to the parathyroid glands. Hypocalcaemia is more frequent in extensive thyroidectomy when compared to minor resections of the thyroid gland, in the ligation of the inferior thyroid artery, and has been related to the surgeon's experience. The mechanism and pathogenesis of hypocalcaemia after thyroid surgery is not completely understood, however, it is

*Baghdad teaching hospital muhsurg@yahoo.com attributed to surgical damage inflicted on the parathyroid glands during thyroidectomy; for example, direct injury, devascularization, or inadvertent removal, vascular injury is probably more important than inadvertent removal.5 Today, correct surgical technique is the most important factor in decreasing the incidence of hypocalcaemia.6 The inferior thyroid artery vessel branches should be handled gently and ligated near to the thyroid.7 Other causative mechanisms that have been implicated in the pathophysiology of post-thyroidectomy hypocalcaemia include calcium uptake by bone in patients with thyrotoxic osteodystrophy, parathyroid suppression from increased calcium restored from the bone of patients with hyperthyroidism, transient post-operative hemodilution with increased renal excretion of calcium, increased release of calcitonin as a result of thyroid manipulation.8 The first clinical sign of hypocalcemia may be less typical and may include numbness and tingling sensation around the mouth and in the distal extremities.9 Physical examination reveals positive Chvostek's sign and Trousseau's sign .Tetany, which is characterized by tonic-clonic seizures, carpopedal spasm and laryngeal stridor, may prove fatal and should be avoided.9 Chronic complications 
are intracranial calcification, particularly of the basal ganglia, various mental disturbances, such as irritability, depression and even psychosis.papilledema and other signs of increased intracranial pressure have been reported. Chronic hypocalcemia may lead to cataract formation and abnormalities of the skin and nails 1 asymptomatic hypocalcemia does not require calcium supplementation, while in patient with severe disturbances or symptoms of hypocalcemia, intravenous supplementation should be implemented and patients should be released with oral calcium and vitamin D regimen until the hypoparathyroidism resolves.10 Intravenous calcium gluconate can be given $10-20 \mathrm{ml}$ of $10 \%$ solution slowly until the symptoms disappear, then $50 \mathrm{ml}$ of $10 \%$ calcium gluconate can be added to $500 \mathrm{ml}$ of $5 \%$ dextrose solution and administered by intravenous drip at a rate of $1 \mathrm{ml} / \mathrm{kg} / \mathrm{h} .11$

\section{Patients and Methods:}

This prospective study was carried out on 100 patients who underwent thyroid surgery for various thyroid diseases at the surgical department of Baghdad teaching hospital in the period between November 2009 to November 2013. The patients included were only those who underwent subtotal, near total and total thyroidectomies. The data form included patient age, gender, muscular built, clinical diagnosis, thyroid function status, type of surgery, ligation of the inferior thyroid artery, pathology report and whether the surgery performed by consultants, senior registrars or residents. Each patient had serum calcium, phosphate and total serum protein measured preoperatively and at day 1, 2, 3, postoperatively. Patients who had postoperative hypocalcaemia were followed up as outpatients and had serial checking of their serum calcium levels. A calcium level of $8 \mathrm{mg} / \mathrm{dl}(2 \mathrm{mmol} / \mathrm{L})$ on at least 2 consecutive measurements was considered as a threshold value of hypocalcaemia, in addition, experiencing symptoms such as perioral and digital paresthesia and having Chvostek's and Trousseau's sign was also included in definition. it was considered transient if it resolved within 6 months and Permanent if it persisted after 6 months and the patient is maintained on supplementation therapy of calcium and vitamin D. Patients who had clinical evidence of hypocalcaemia (circumoral and acral (fingers and toes) paresthesia, and carpopedal spasm were given i.v. calcium gluconate, $10-20 \mathrm{ml}$ of $10 \%$ solution until the signs and symptoms disappear. Some patients require the dose to be given 2-3 times per day. Patients who had permanent hypocalcaemia were given oral calcium vitamin D supplementations and were followed up on regular checking up visits. The histopathological report was reviewed and the results were compared with the state a hypocalcaemia.It was not feasible to perform a parathyroid hormone level assay because this test was not available at our hospital lab.

\section{Results:}

A total of 100 patients aged from 20 to 70 years underwent a thyroidectomy 92 were females and 8 were males. The Distribution of 100 patients who underwent surgery according to various thyroid diseases was Multi nodular goiter 72, Grave's disease10, Toxic nodular goiter 8, Thyroiditis 6, Cancer 4. Distribution of 100 patients according to type of the surgical procedure for various thyroid diseases is shown in table (1).

Table (1): Distribution of 100 patients according to type of the surgical procedure for various thyroid diseases.

\begin{tabular}{lllllll}
\hline $\begin{array}{l}\text { Type of } \\
\text { Surgery }\end{array}$ & $\begin{array}{l}\text { No. } \\
\text { of } \\
\text { Patien } \\
\text { ts }\end{array}$ & $\begin{array}{l}\text { MN } \\
\text { G }\end{array}$ & $\begin{array}{l}\text { C } \\
\text { A }\end{array}$ & $\begin{array}{l}\text { Thyroidi } \\
\text { tis }\end{array}$ & $\begin{array}{l}\text { Grave } \\
\text { s }\end{array}$ & $\begin{array}{l}\text { Toxic } \\
\text { Nodul } \\
\text { ar } \\
\text { Goiter }\end{array}$ \\
\hline $\begin{array}{l}\text { Total } \\
\text { Thyroidecto } \\
\text { my }\end{array}$ & 9 & 0 & 4 & 0 & 3 & 2 \\
\hline $\begin{array}{l}\text { Near total } \\
\text { Thyroidecto } \\
\text { my }\end{array}$ & 22 & 9 & 0 & 2 & 6 & 5 \\
\hline $\begin{array}{l}\text { Subtotal } \\
\text { Thyroidecto } \\
\text { my }\end{array}$ & 69 & 63 & 0 & 4 & 1 & 1 \\
\hline
\end{tabular}

The distribution of 100 patients who underwent surgery according to the type of the surgical procedure and its related transient \& permanent hypocalcaemia is summarisedin table (2).

Table (2): The distribution of 100 patients who underwent surgery according to the type of the surgical procedure and its related transient \& permanent hypocalcaemia.

\begin{tabular}{llllll}
\hline $\begin{array}{l}\text { Type } \\
\text { surgery }\end{array}$ & $\begin{array}{l}\text { No. of } \\
\text { patient } \\
\mathrm{s}\end{array}$ & $\begin{array}{l}\text { hypoclcaemi } \\
\mathrm{a}\end{array}$ & $\begin{array}{l}\text { yes } \\
\text { Transien } \\
\mathrm{t}\end{array}$ & $\begin{array}{l}\text { no } \\
\text { Permanen } \\
\mathrm{t}\end{array}$ \\
\hline $\begin{array}{l}\text { Total } \\
\text { thyroidectom } \\
\mathrm{y}\end{array}$ & 9 & 8 & 1 & 5 & 3 \\
\hline Near total & 22 & 10 & 12 & 8 & 2 \\
\hline $\begin{array}{l}\text { Subtotal } \\
\text { thyroidectom } \\
\mathrm{y}\end{array}$ & 69 & 12 & 57 & 11 & 1 \\
\hline Total & 100 & 30 & 70 & 24 & 6 \\
\hline
\end{tabular}

$30 \%$ of patients developed hypocalcaemia postoperatively; in $24 \%$ of them it was transient and in $6 \%$ was permanent. 3 of the 6 patients who developed permanent hypocalcaemia had underwent total thyroidectomy and the other 2 had underwent near total thyroidectomy and the last patient had underwent subtotal thyroidectomy. Table (3) P-value $=0.001$ All the patients with $\mathrm{CA}$ had post thyroidectomy hypocalcaemia, while $66.66 \%$ of patients with thyroiditis had hypocalcaemia and only $50 \%$ of those with Grave's disease had hypocalcaemia, and $37.55 \%$ of those with toxic nodular goiter had hypocalcaemia and only $19.45 \%$ of those with simple multi nodular 
goiter had hypocalcaemia. Table (3). Distribution of 100 patients who underwent surgery according to the type of the surgical procedure, histopathological report and their related hypocalcaemia. Table (3)

Table (3): Distribution of 100 patients who underwent surgery according to the type of the surgical procedure, histopathological report and their related hypocalcaemia

\begin{tabular}{|c|c|c|c|c|c|c|c|}
\hline $\begin{array}{l}\text { Type of } \\
\text { surgery }\end{array}$ & $\begin{array}{l}\text { Num } \\
\text { ber } \\
\text { of } \\
\text { patie } \\
\text { nts }\end{array}$ & $\begin{array}{l}\text { Hypocalc } \\
\text { emic }\end{array}$ & $\begin{array}{l}\mathrm{MN} \\
\mathrm{G}\end{array}$ & $\begin{array}{l}\mathrm{C} \\
\mathrm{A}\end{array}$ & - & $\begin{array}{l}\text { Grav } \\
\text { e's }\end{array}$ & $\begin{array}{l}\text { Toxi } \\
\mathrm{c} \\
\text { Nodu } \\
\text { lar } \\
\text { Goitr } \\
\mathrm{e}\end{array}$ \\
\hline $\begin{array}{l}\text { Total } \\
\text { Thyroidec } \\
\text { tomy }\end{array}$ & 9 & 8 & & 4 & & 3 & 1 \\
\hline $\begin{array}{l}\text { Neartotal } \\
\text { Thyroidec } \\
\text { tmy }\end{array}$ & 22 & 10 & 4 & & 2 & 2 & 2 \\
\hline $\begin{array}{l}\text { Subtotal } \\
\text { Thyroidec } \\
\text { tomy }\end{array}$ & 69 & 12 & 10 & & 2 & & \\
\hline
\end{tabular}

22 patients out of the $24(91.66 \%)$ who developed transient hypocalcaemia were females, and 5 patients out of the 6 (83.33) who developed permanent hypocalcaemia were females also. P-value $=0.501$. The incidence of hypocalcaemia in relation to the gender of total 30 patient was 3 male (1 permanent, 2 transient) and 27 female (5 permanent, 22 Transient) The incidence of hypocalcaemia in relation to the operator in 31 patients were operated on by a consultant surgeon, and 7 patients out of those $(22.5 \%)$ had hypocalcaemia, 19 patients were operated on by a senior registrar and 6 patients of those $(31.5 \%)$ had hypocalcaemia and 50 patients were operated on by the residents and 17 patients of those (34\%) had hypocalcaemia. $\mathrm{P}$ value $=0.54$. All of the patients who underwent total and near total thyroidectomy (31 patients) had underwent a bilateral ligation of the inferior thyroid artery, 20 patients of them $(66.6 \%)$ had hypocalcaemia, while 30 patients out of the 69 who underwent subtotal thyroidectomy had underwent a unilateral ligation of the inferior thyroid artery, and only 10 of them $(33.4 \%)$ had hypocalcaemia postoperatively. $\mathrm{P}$-value $=0.01$, Table (4).

Table (4): The incidence of hypocalcaemia in relation to the ligation of the inferior thyroid artery.

\begin{tabular}{|c|c|c|c|c|c|c|}
\hline \multirow{3}{*}{$\begin{array}{l}\text { Ligation of } \\
\text { the Inferior } \\
\text { Thyroid } \\
\text { Artery }\end{array}$} & \multicolumn{4}{|c|}{ Hypocalcaemia } & \multirow{2}{*}{\multicolumn{2}{|c|}{ total }} \\
\hline & \multicolumn{2}{|l|}{ Yes } & \multicolumn{2}{|l|}{ No } & & \\
\hline & No. & $\%$ & No. & $\%$ & No. & $\%$ \\
\hline Bilateral & 20 & 66.6 & 11 & 35.4 & 31 & 50.9 \\
\hline Unilateral & 10 & 33.4 & 20 & 64.6 & 30 & 49.1 \\
\hline Total & 30 & 50 & 31 & 50 & 61 & 100.0 \\
\hline
\end{tabular}

The incidence of hypocalcaemia in relation to the muscular built of the patient was that, 8 patients who developed hypocalcaemia out of 9 total thyroidectomy were of normal or under normal muscular built, with only one patient out of the 10 who had hypocalcaemia following 22 near total thyroidectomy was obese and of short neck and two patient out of 12 who had hypocalcaemia following 69 subtotal thyroidectomy were obese and of short neck also.

$33.4 \%$ of the patients who had transient hypocalcemia were between 31-40 years of age, $25 \%$ were between 20-30 years of age, $16.6 \%$ were between $41-50$ years, $16.6 \%$ were between 51-60 years and finally $8.4 \%$ were between $61-70$ years.66.6\% of the patients who had permanent hypocalcaemia were between 31-40 years of age, $16.7 \%$ were between $20-30$ and 41-50 years of age. Table (5).

Table (5): The incidence of hypocalcaemia in relation to the age group.

\begin{tabular}{lllllll}
\hline \multirow{2}{*}{ Age } & \multicolumn{2}{l}{ Hypocalcaemia } & \multicolumn{2}{c}{ Total } \\
\cline { 2 - 6 } & \multicolumn{2}{l}{ Permanent } & \multicolumn{2}{c}{ Transient } & \multicolumn{2}{c}{} \\
\cline { 2 - 6 } & No. & $\%$ & No. & $\%$ & No. & $\%$ \\
\hline $20-30$ & 1 & 16.7 & 6 & 25.0 & 7 & 23.4 \\
\hline $31-40$ & 4 & 66.6 & 8 & 33.4 & 12 & 40.0 \\
\hline $41-50$ & 1 & 16.7 & 4 & 16.6 & 5 & 16.6 \\
\hline $51-60$ & 0 & 0.00 & 4 & 16.6 & 4 & 13.3 \\
\hline $61-70$ & 0 & 0.00 & 2 & 8.4 & 2 & 16.7 \\
\hline Total & 6 & 20.0 & 24 & 80.0 & 30 & 100.0 \\
\hline
\end{tabular}

\section{Discussion}

Postoperative hypocalcaemia is a relatively common complication of thyroid surgery and is known as a major cause of postoperative morbidity, but most often it is a transient event that occurs mostly after extensive thyroid surgery. The reported incidence of transient hypocalcaemia ranges from $1.6 \%-9.3 \%$ after subtotal thyroidectomy and from $6.9 \%$ - $42 \%$ after total thyroidectomy. In contrast, permanent hypocalcaemia has been reported in $0.2-3 \%$ of patients after subtotal thyroidectomy and in $0.4-29 \%$ of patients after total thyroidectomy. ${ }^{1}$ The result of our study showed that the incidence of hypocalcaemia is $30 \%$ and it was transient in the majority of the cases. Review of literature revealed that the prevalence of RLN palsy varies from centre to centre depending upon the level of experience in thyroid surgery and the nature of surgery. Transient and permanent RLN palsy, $2.58 \%$ and $0.64 \%$ respectively, was observed also in Ishtiaq Ahmed study ${ }^{12}$ Aytec and colleagues ${ }^{13}$ reported $3.5 \%$ and $1.2 \%$ incidence of transient and permanent RLN injury, respectively, whereas, Chaing ${ }^{14}$, has reported figures of $5.1 \%$ and $0.9 \%$ for transient and permanent RLN injury. $\mathrm{Xu}$ and colleagues ${ }^{15}$ have reported $0.2 \%$ incidence of permanent RLN injury in their study in China. Schulte ${ }^{16}$ has reported prevalence of RLN palsy in the range of $0.5 \%-2.5 \%$, from Australia. In Pakistan, an incidence of $4.7 \%$, both for transient and permanent RLN palsy has been reported in a study by 
Arif and his colleagues ${ }^{17}$. On the other hand, Shahand his colleagues ${ }^{18}$ have reported it to be $13.5 \%$ Regarding the age, most of the patients who had transient hypocalcaemia $(33.4 \%)$ belong to the $31-40$ years age group, and most of the patients who had permanent hypocalcaemia (66.6) belong to that age group also, which is nearly similar to Ishtiaq ahmed et al ${ }^{12}$ study ,but An increase in age did not increase risk of developing post-thyroidectomy hypocalcaemia $(\mathrm{p}=$ 0.697), ${ }^{19}$ Regarding the gender, most of the patients who had transient hypocalcaemia (91.66\%) were females, and most of the patients who had permanent hypocalcaemia $(83.3 \%)$ were females also, which is similar to Thomuusch etal study ${ }^{20}$. (P-value $=0.501$ The peak incidence of thyroid abnormalities in our study occurred in patients above 40 years $(52.9 \%)$ and of these majority were females $(82.1 \%)$. A similar study conducted also had a sex ratio of 1:4.92 in favor of females. ${ }^{21,22}$ The incidence of hypocalcaemia was more in patients over 40 years of age and seen more in females. This may be probably due to the fact that there were more females presenting with thyroid symptoms in our study and the majority of patients were above 40 years of age. But the association was not found to be statistically significant. 20, 22 Regarding the type and extent of the surgical procedure, we found that the incidence of transient hypocalcaemia was $55.5 \%$ after total thyroidectomy, while it was $36.3 \%$ after near total thyroidectmy and it was only $15.9 \%$ after subtotal thyroidectomy.(P-value $=0.001)$. The incidence of permanent hypocalcaemia was $33.3 \%$ after total thyroidectomy while it was $9 \%$ after near total thyroidectomy and only $1.4 \%$ after subtotal thyroidectomy. Similarly, patients undergoing total thyroidectomy or lobectomy and subtotal thyroidectomy are more at risk of getting RLN injury; $7.69 \%$ and $6.25 \%$ respectively had transient and $3.84 \%$ and $6.25 \%$ respectively developed permanent RLN injury. Literature revealed comparable observation from different studies carried out at different centers in the world. 12, 13, 14,16,17,23 These figures are consistent with those reported in other studies (Ishtiaq Ahmed et al) ${ }^{12}$ that showed that the extent of resection and surgical technique has greater impact on the rate of post-thyroidectomy hypocalcaemia. Regarding the ligation of the inferior thyroid artery, we found that $66.6 \%$ of the patients who underwent bilateral ligation of that artery had post-thyroidectomy hypocalcaemia, while $33.4 \%$ of the patients who underwent a unilateral ligation of that artery had hypocalcaemia, so making that procedure as an important risk factor. $(\mathrm{P}$-value $=0.01)$. These figures are consistent with those reported in other studies (Ishtiaq Ahmed et al). ${ }^{12}$ Regarding the experience of the operator, we found that the incidence of post-thyroidectomy hypocalcaemia in patients whom surgery was performed by consultant surgeon was $22.5 \%$, while in those operated on by registrar was $31.5 \%$ and those whom operated on by residents was
34\%. $(\mathrm{P}$-value $=0.54)$. Regarding the clinical and the pathological diagnosis, we found that All the patients with CA had post thyroidectomy hypocalcaemia (Pvalue $=0.006)$, while $66.66 \%$ of patients with thyroiditis had hypocalcaemia $(\mathrm{P}$-value $=0.06)$ and only $50 \%$ of those with Grave's disease had hypocalcaemia, and 37.55 of those with toxic nodular goiter had hypocalcaemia and only 19.45 of those with simple multi nodular goiter had hypocalcaemia. These findings are in agreement with other studies (which is similar to Thomuusch et al study20), which showed that the thyroid cancer is a risk factor for inadvertent parathyroid excision. In addition, the overall frequency of postoperative low calcium levels in Seyed Mostafa Shiryazdi1 study was found nearly $83 \%$ of patients, also they did not find a significant relation between postoperative hypocalcemia and calcium low levels with possible risk factors such as the patient gender $(\mathrm{P}=0.56)$, age $(\mathrm{P}=0.73)$, thyroid pathology $(\mathrm{P}=0.56)$, the presence or not presence of parathyroid tissue $(\mathrm{P}=0.58)$ or the type of thyroidectomy $(\mathrm{P}=0.79)$. Regarding the muscular built of the patient, we found that only $10 \%$ of the patients who had post thyroidectomy hypocalcaemia were obese and of a short neck, so making that parameter is not so significant. Regarding the muscular built of the patient, we found that only $10 \%$ of the patients who had post thyroidectomy hypocalcaemia were obese and of a short neck, so making that parameter is not so significant.

\section{Conclusions:}

We concluded that post thyroidectomy hypocalcemia is a relatively common complication, but it is transient in the majority of the patients. Its incidence is related to the extent of the surgery and can be reduced by the use of the correct surgical procedures.

\section{Authors' contribution:}

Mohannad Kamel Al-Bermani: Study conception, critical revision, writing of manuscript, designs the protocol of the study.

Aws Basheer Abed: selection of study subject, Selection of samples, acquisition of data, writing of manuscript, Interpretation, collection and analyses of data.

Waleed abdul hussain Salman: support in writing the theses, drafting and manuscript, statistical analysis.

\section{References}

1. Hitoshi miki, hiroyuki inoue, masayo kitaichi, et al. Estimation of free calcium levels after thyroidectomy, the journal of medical investigation jmi. 2009; 44:1-2.

2. Norman s. Williams, christopher j.k. Bulstrode, p. Ronan o'connell, bailey \& love's, short practice of surgery. London, edward arnold ltd.2008.p. 791.

3. Ali khairalla shaaeli. The incidence and risk factors of hypocalcaemia in post thyroidectomy 
patients, prospective study at al-hilla teaching hospitalijmps. 2015; 5(8): 01-05

4. G.r. Qasaimeh, y. Khade, f.m. Al-mohamed, et al.post thyroidectomy hypocalcemia, bioline international. 2009; 14: 32-37.

5. Courtney m. Townsend, r. Daniel beauchamp, $b$. Mark evers, kenneth l. Mattox, sabiston textbook of surgery. Philadelphia, elsevier saunders .2004.p.981.

6. Antonio jose goncalves, laercio martins, tania regina bastos de souza,et al. Clinical and laboratorial correlation of postoperative hypocalcemia after extensive thyroidectomy, sao paulo medical journal.2000; 115:1.

7. Pramod $k$ sharma. Complications of thyroid surgery,

http://emedicine.medscape.com/article/852184-

overview.

8. Alfred cuschieri, robert j.c. Steele, abdool rahim moossa, essential surgical practice. London, oxford university press.2002.p.110.

9. Douglas w. Wilmore, laurence y. Cheung, alden $h$. Harken, american college of surgeons acs. New york, webmd professional publishing.2003.p.603.

10. Faiza a qari. Estimation of ionized calcium after thyroidectomy, kuwait medical journal.2005; 37:169172.

11. F. Charles brunicardi, dana $k$. Andersen, timothy $r$. Billiar ,david l. Dunn, john g.hunter, raphael $e$. Pollock, schwartz's principles of surgery. Newyork, mcgraw-hill.2014, 9, chapter 18, page 565.

12.jayub med coll abbottabad,ishtiaq ahmed chaudhary, samiullah, rehan masood, muhammad ashraf majrooh,ashraf ali mallhi,recurrent laryngeal nerve injury: an experience with 310 thyroidectomies. 2007; 19(3) 46

13. Aytac b, karamercan a. recurrent laryngeal nerve injury and preservation in thyroidectomy. Saudi med $j$. 2005; 26 (11):1746-9.
14. Chiang fy, lee kw, huang yf, wang lf, kuo wr. Risk of vocal palsy after thyroidectomy with identification of the recurrent laryngeal nerve. Kaohsiung $j$ med sci 2004; 20(9):431-6.

15.Xu $x f$, wang $x$, wang $c y$, lin $n$, wang ny. Specialization in thyroid surgery. Zhonghua er bi yan hou tou jing wai ke za zhi. 2005 Jun; 40(6):431-4.

16. Schulte $\mathrm{km}$, roher hd. Complications in the surgery of benign thyroid disease. Acta chir austriaca. 2001; 33(4): 164-72

17. Arif $m$, ahmed $i$. Recurrent laryngeal nerve palsy during thyroidectomies. J surg pakistan. 2001;6(3):125

18. Shah ssh, khan a. Assessment of complications of total thyroidectomy. J surg pakistan. 2005; 10(3):24-6. 19. Mwige, peace mukami, incidence of postthyroidectomy hypocalcaemia in kenyatta national hospital.university of nairobi.november, department of surgery, ,uonbi.ac.ke.medschool, surgery 2014.

20. Thomuusch etal study, viswanathan $k v$, jithunath $m r$, manjusha viswanathan incidence of post-operative hypocalcaemia after thyroidectomy: a case control study international journal of advanced health sciences, september 2014 , vol 1 , issue 5

21. Nair cg, babu mj, menon $r$, jacob $p$. Hypocalcaemia following total thyroidectomy: an analysis of 806 patients. Indian $j$ endocrinol metab. 2013 mar $1 ; 17(2): 298$.

22. Liu q, djuricin g, prinz ra. Total thyroidectomy for benign thyroid disease. Surgery. 1998 jan;123(1):2-7

23. Mchenry cr. Patient volumes and complications in thyroid surgery. Br j surg. 2002;89(7):821-23

24. Seyed mostafa shiryazdil, saeed kargarl*, mohammad afkhami-ardekani2, and hossein neamatzadeh3, risk of postoperative hypocalcemia in patients underwent total thyroidectomy, subtotal thyroidectomy and lobectomy surgeries,received: 14 jan. 2013. 